of this work formed three lectures which were recently delivered at the Royal Institute of Public Health, and the fourth chapter is upon the subject of sterilisation. This term is restricted in its application to the destruction of microbes causing epidemic water-borne disease; and the methods set out embrace the "excess lime" treatment (which is Dr. Houston's own suggestion) and the "chlorination" of water.

Some persons may consider that Dr. Houston takes too sanguine a view with regard to the safety of rivers as sources of water-supply. There can be no doubt, however, that the large amount of experimental work he has undertaken, notably that which illustrates the prime value of storage as a means of reducing the risk of water-borne disease, justifies his sanguine views. After all, where London has succeeded other towns can also succeed, always provided that in these other towns the same careful working is maintained by a well-trained personnel as is the case with London, and that a similar constant and scientific control of the state of the water is maintained. The danger is that these provisions may not always be made.

The American Indians North of Mexico. By W. H. Miner. Pp. $x+169$. (Cambridge: At the University Press, I9I7.) Price $3 s$. net.

THE literature connected with the North American Indians is so extensive that a readable summary of it in a popular form was much needed for the use of European anthropologists commencing the study. In America, particularly among the descendants of the hardy frontier men, the question is attracting increased attention. This want is well supplied in this book. The advanced student will depend not only on the classical works of Bancroft, Schoolcraft, and Catlin, but also on the monographs published by the Bureau of American Ethnology and other societies which have been summarised, with the addition of much new matter, by Mr. F. W. Hodge in his excellent "Handbook of American Indians North of Mexico." The questions connected with the origin of these tribes still form the subject of controversy. The writer remarks that the general consensus of opinion during the last century is to the effect that, "with the exception of the Eskimo, the natives of America are wholly of one race and descendants from early emigrants from north-eastern Asia, and especially of Mongolian stock." But the movements of these people within the American continent have as yet not been definitely settled. The importance of linguistics for the settlement of these problems is fully recognised. The book, after a summary account of the environment, discusses the sociology of the tribes, and gives details of some members of the Plains Indians and those of the south-west. The culture of the Pueblos forms the subject of an interesting chapter. There is a good bibliography, and the book may be commended as a satisfactory popular introduction to the study of a remarkable people.

NO. 2484, VOL. 99]

\author{
LETTERS TO THE EDITOR.
}

[The Editur does not hold himself responsible for opinions expressed by his correspondents. Neither can he undertake to return, or to correspond with the writers of, rejected manuscripts intended for this or any other part of NATURE. No notice is taken of anonymous communications.]

\section{The Origin of Flint.}

May I ask you to publish the following notes on the origin of flint? I understand that a discussion of the subject has been initiated by those interested in the chemical and physical aspects of geology, and think that the facts cited below may be of interest at this moment.

I understand by the term "the origin of flint" an account or reasonable explanation of the formation of the nodules of black flint which occur so abundantly in stratified layers in the Upper Chalk of this country.

Some seventy years ago the view was put forward by the well-known naturalist Bowerbank-who was a special student of the sponges-that the flint nodules of the chalk were formed in situ in the depths of the sea by the silicification of sponges which already contained abundant siliceous spicules, and were, as it were, solidified by attracting to themselves additional silica from the sea-water. Silicification of wood-as in the case of some wooden piers erected in shallow seas -was known. The segregation of silica by the attraction for it of organic matter was a recognised fact. Similar segregation and formation of "concretions" of other chemical substances by other attractive nuclei was recognised. Thus lumps or small masses of clay were shown to have the power of attracting phosphate of lime, and so to give rise to those "phosphatic" nodules found at the base of the Red and Coralline Crag, and also at the base of the Cambridge Greensand, and in other positions where the bones of animals were accumulated and furnished phosphate of lime, which was first dissolved by the seawater and then removed from it and held by the clay nodules.

From time to time other views were put forward as to the formation of the flint-nodules of the chalk after the deposit of the chalk yet whilst it was still beneath the sea and permeated by sea-water. It was held that the organic remains deposited in strata in the chalk sea-bottom exercised an attractive influence on the silica dissolved in sea-water, and so led to the replacement of the organic remains by solid silica. Later it became fairly certain that, as is the case with the Atrantic ooze, the chalk deposit contained originally about to per cent. of colloid silica in the form of spicules and skeletons of minute organisms, and it was held that this silica was dissolved by the permeating sea-water (whilst the chalk was still beneath the sea), and was then separated and deposited in the cavitios occupied by sponges and other organic remains in stratified layers in the chalk.

It is difficult enough to find a parallel for this supposed deposit when the solid, fairly (though not completely) homogeneous character of the black chalk flint is borne in mind. It is remarkable that the flint deposited in these cavities shows little or no trace of onion-like concentric layering, such as characterises the agates formed in geodes of igneous rock. We also are met with a striking fact, namely, that the black flint is apparently micro-crystalline in structure, and that its behaviour when "weathered" is such as to lead to the inference that, although homogeneous to the unaided eye, it yet consists of minute particles of quartz (that is to say, crystalline silica of the same nature as rock-crystal) cemented by colloid silica, which latter dissolves to a certain extent in alkaline 